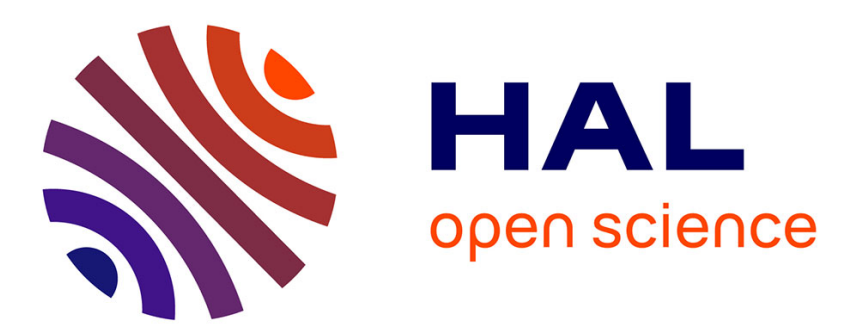

\title{
Suppressing Structural Colors of Photocatalytic Optical Coatings on Glass: The Critical Role of SiO2
}

Ronghua Li, Mickael Boudot, Cédric Boissière, David Grosso, Marco Faustini

\section{To cite this version:}

Ronghua Li, Mickael Boudot, Cédric Boissière, David Grosso, Marco Faustini. Suppressing Structural Colors of Photocatalytic Optical Coatings on Glass: The Critical Role of SiO2. ACS Applied Materials \& Interfaces, 2017, 9 (16), pp.14093-14102. 10.1021/acsami.7b02233 . hal-01510238

\section{HAL Id: hal-01510238 https://hal.sorbonne-universite.fr/hal-01510238}

Submitted on 19 Apr 2017

HAL is a multi-disciplinary open access archive for the deposit and dissemination of scientific research documents, whether they are published or not. The documents may come from teaching and research institutions in France or abroad, or from public or private research centers.
L'archive ouverte pluridisciplinaire HAL, est destinée au dépôt et à la diffusion de documents scientifiques de niveau recherche, publiés ou non, émanant des établissements d'enseignement et de recherche français ou étrangers, des laboratoires publics ou privés. 


\section{Suppressing structural colors of photocatalytic}

\section{optical coatings on glass: the critical role of}

\section{$\mathrm{SiO}_{2}$}

Ronghua Li ${ }^{l}$, Mickael Boudot ${ }^{l, 2}$, Cédric Boissière ${ }^{l}$, David Grosso $^{3}$, Marco Faustini $^{1 *}$

${ }^{1}$ Sorbonne Universités, UPMC Univ Paris 06, CNRS, Collège de France, UMR 7574, Chimie de la Matière Condensée de Paris, F-75005, Paris, France.

${ }^{2}$ Institute for Materials Chemistry and Engineering, Kyushu University, 6-1 Kasuga-Koen, Kasuga, Fukuoka 816-8580, Japan.

${ }^{3}$ IM2NP, Faculté des Sciences et Techniques, Campus de Saint Jérôme, Avenue Escadrille Normandie Niemen, 13397 Marseille, France 


\title{
KEYWORDS
}

Interference, structural color, photocatalytic, optical coatings, mesoporous

\begin{abstract}
The appearance of structural colors on coated-glass is a critical esthetical drawback toward industrialization of photocatalytic coatings on windows for architecture or automobile. Herein we describe a rational approach to suppress the structural color of mesoporous $\mathrm{TiO}_{2}$-based coatings preserving photoactivity and mechanical stiffness. Addition of $\mathrm{SiO}_{2}$ as third component is discussed. $\mathrm{Ti}_{\mathrm{x}} \mathrm{Si}_{(1-\mathrm{x})} \mathrm{O}_{2}$ mesoporous coatings were fabricated by one-step liquid deposition process through the evaporation induced self-assembling and characterized by GI-SAXS, GIWAXS, electron microscopies and in-situ Environmental Ellipsometry Porosimetry. Guided by optical simulation, we investigated the critical role of $\mathrm{SiO}_{2}$ on the optical responses of the films but also on the structural, mechanical and photocatalytic properties, important requirements to go toward real applications. We demonstrate that, adding $\mathrm{SiO}_{2}$ to porous $\mathrm{TiO}_{2}$ allows tuning and suppression of structural colors through refractive index matching and up to $160 \%$ increase in mechanical stiffening of the films. This study leads us to demonstrate an example of "invisible" coating, in which the light reflection is angle- and thickness- independent, and exhibiting high porosity, mechanical stiffness and photoactivity.
\end{abstract}




\section{INTRODUCTION}

Glass is an outstanding material, massively employed in everyday life such as in optical devices, architecture, automobile and arts. ${ }^{1}$ In addition to its transparency and insulating properties it is mainly appreciated to be chemically inert. However, additional functionalities can be integrated in standard glasses by applying optical coatings. Among them, photocatalytic coatings allow the glass surface to be "reactive", enabling decomposition of organic species under light irradiation. ${ }^{2}$ Two main properties have been targeted: (i) self-cleaning capabilities, allowing decomposition of non-volatile organic species from the surface (dirt, contaminations) ${ }^{3}$ that affect the glass appearance; (ii) air depollution of volatile organic compounds especially in the case of odorous and harmful molecules. ${ }^{4-6}$ Among the requirements demanded to be applied on glass, this "reactive" coating must be highly photoactive with high surface area, non-light absorbing and non-light scattering light in the visible range and must exhibit good mechanical, chemical and thermal stability. In such domain, $\mathrm{TiO}_{2}$ based mesoporous coatings have been considered as most serious candidates. ${ }^{7-8}$ Optical quality nanocrystalline $\mathrm{TiO}_{2}$ mesoporous films can be obtained by sol-gel process in presence of templating agents ${ }^{9-10}$ and can be easily applied by liquid deposition techniques on large surfaces making this material appealing for industrial production. $^{11}$

Despite the fact that massive research was conducted in the field of porous photocatalytic films, the lab-to-market transition is still hindered. ${ }^{12-13}$ One of the main reasons is related to the esthetical appearance of the coated-glass. Indeed, when the refractive index dispersion of the coating differs from that of glass substrate, structural colors are observed due interference phenomena taking place at air/coating/glass interfaces. ${ }^{14-15}$ Coatings having homogenous thickness produce an angle-dependent shade that is not suitable for design conception in many applications especially for architectural windows or automobile windshields. This (un) esthetical effect is even more problematic when the coating's thickness is not homogenous over the surface. In fact, thickness fluctuations result in color fluctuation visible at naked eye. ${ }^{16}$ 
Thickness fluctuations can be produced during the film deposition due to not controlled process conditions, dust or to edge effects; ${ }^{17}$ thickness inhomogeneity can also appear within time due to damaging of the films by delamination, dissolution or scratching. There is thus a strong need for the development of high surface area, photoactive films exhibiting "invisibility" on glass. The most straightforward way to suppress the structural colors consists in applying coatings that match the refractive index of glass all over the visible range of wavelengths. Due to the intrinsic high refractive index of $\mathrm{TiO}_{2}(\mathrm{n}=2.2-2.5$ in the visible range $)$ as compared to commercial glass ( $\mathrm{n} \approx 1.5$ in the visible range), one option to approach the refractive index matching would consist in increase the porosity $\%$ vol of $\mathrm{TiO}_{2}$ coatings up to $60 \%$; however this solution would lead to mechanically fragile films. Alternatively, a low refractive index material, such as silica, can be added in the network. Nanocomposite $\mathrm{SiO}_{2}-\mathrm{TiO}_{2}$ mesoporous coatings have been already proposed in the literature mainly to target anti-reflectivity and photocatalytic capabilities; ${ }^{18-19}$ however even anti-reflective interferential coatings always exhibit angle-dependent structural colors. In addition, compared to anti-reflection, the conditions required for "invisibility" are stricter since the refractive index dispersion law should precisely match the one of glass in all the range of wavelengths. The development of such invisible coatings is challenging since addition of silica induces not only a decrease of refractive index (to reach invisibility) but also a modification of the structural, mechanical and photocatalytic properties of the porous layers, important requirements to go toward real applications.

In this work, we report a rational approach to design mesoporous photoactive, invisible coatings and we discuss the critical role of $\mathrm{SiO}_{2}$ on the structural, optical and photocatalytic properties of the films. Starting from the experimental refractive index dispersion law, the formation and the suppression of the reflected structural colors could be systematically predicted by using simulation. Guided by these results, photocatalytic $\mathrm{TiO}_{2}-\mathrm{SiO}_{2}$ mesoporous coatings were fabricated by a one-step liquid deposition process using the evaporation induced self-assembly method, using F127 block copolymer as an organic template mixed with various $\mathrm{TiO}_{2}$ and $\mathrm{SiO}_{2}$ 
molecular precursors' ratios in ethanolic solution. We experimentally confirmed that such composite mesoporous coatings perform as colored antireflective and reflective coatings and only a precise combination of the three phases $\left(\mathrm{TiO}_{2}, \mathrm{SiO}_{2}\right.$ and air) allows obtaining invisibility, improved mechanical stiffness and high photocatalytic activity. Importantly, we highlight the critical role of silica on the final porous structure, stiffness and photocatalytic performances of the films as characterized by GI-SAXS, GI-WAXS, SEM-FEG, TEM and in situ Environmental Ellipsometry Porosimetry (EEP).

\section{Experimental details}

Chemical Solutions. Absolute ethanol (EtOH) was purchased from Normapur while TEOS (tetraethylorthosilicate), $\mathrm{TiCl}_{4}$ (titanium IV chloride), hydrochloride acid $(2 \mathrm{M} \mathrm{HCl}), \mathrm{F} 127$ Pluronic $\left(\mathrm{EO}_{106} \mathrm{PO}_{70} \mathrm{EO}_{106}\right)$ were purchased from Aldrich. All products were used as received. $\mathrm{TiO}_{2}-\mathrm{SiO}_{2}$ composite mesoporous thin films were prepared from solutions composed of $\mathrm{TiCl}_{4} / \mathrm{TEOS} / \mathrm{F} 127 / \mathrm{EtOH} / \mathrm{H}_{2} \mathrm{O}$ with respective molar ratios of $1-\mathrm{x} / \mathrm{x} / 0.006 / 30 / 10$ with $0 \leq \mathrm{x} \leq$ 0.98. Pure silica mesoporous films solutions were prepared from solutions composed of TEOS/F127/EtOH/ $\mathrm{H}_{2} \mathrm{O} / \mathrm{HCl}$ with respective molar ratios of $1 / 0.006 / 40 / 5 / 0.005$. Solutions were obtained by dissolving the inorganic precursors in ethanol and water followed by addition of F127. In case of mesoporous pure silica films, $2 \mathrm{M} \mathrm{HCl}$ was added to hydro-alcoholic phase to ensure the hydrolysis of the precursor. ${ }^{20-21}$

Films Processing. The oxide films were prepared by dip coating, using an Acedip dip coater, onto silicon wafer or glass at room temperature $\left(\approx 22^{\circ} \mathrm{C}\right)$, at low relative humidity $(\mathrm{RH}<2 \%)$ and at a typical withdrawal speed of $3 \mathrm{~mm} \cdot \mathrm{s}^{-1} \cdot{ }^{22}$ As-prepared composite films were then aged in humid atmosphere $\left(\mathrm{RH}=75 \%, 37^{\circ} \mathrm{C}\right)$ for $10 \mathrm{~min}$. After the aging, $\mathrm{TiO}_{2}-\mathrm{SiO}_{2}$ and pure silica 
films were calcined for 10 min underneath a curing IR lamp at $600^{\circ} \mathrm{C}$ on silicon substrates and glass substrates whatever the chemical composition of thin films.

Characterization. For grazing incidence small-angle X-ray scattering (GI-SAXS), a Rigaku Smax 3000 apparatus equipped with a microfocus source $\lambda=0.154 \mathrm{~nm}$ and a 2D Gabriel type detector placed at $1480 \mathrm{~mm}$ from the sample was used. The angle of incidence was $0.2^{\circ}$. Diffraction patterns were interpreted using Igor software 13. Wide-angle X-ray scattering (GIWAXS) used the same setup as for GI-SAXS except that diagrams were obtained by radial integration of the signal obtained on an image plate placed at $5 \mathrm{~cm}$ from the sample center. Microscope images showing the film structure were collected using a field-emission gun scanning electron microscopy (SEM-FEG) Hitachi SU7000 instrument. Ellipsometry measurements were performed on a UV-visible (from 245.5 to $998.86 \mathrm{~nm}$ ) variable angle spectroscopic ellipsometer (VASE-2000U Woolam). The data analyses and optical simulations were performed with Wvase32 software using a Cauchy models. Porous structures were assessed by Environmental Ellipsometry Porosimetry (EEP) that was carried out through capillary condensation of water into the porosity with a controlled atmosphere cell in which relative humidity was controlled by mass flow controllers.

Photocatalytic Tests. Photoactivity of the composite systems was investigated in controlled environmental conditions $\left(\mathrm{RH}=40 \%, \mathrm{~T}=22 \pm 2^{\circ} \mathrm{C}\right)$ by monitoring the refractive index of the contaminated layers under UV irradiation. Lauric acid (LA) was chosen as model contaminant to fill the mesoporosity of composite films and deposited by dip coating from a $0.5 \mathrm{wt} \% \mathrm{LA}$ solution in ethanol. The polluted samples were then placed into the ellipsometer environmental chamber $4 \mathrm{~cm}$ under the UV lamp $\left(365 \mathrm{~nm} / 41.1 \mathrm{~mW} . \mathrm{cm}^{-2}\right)$. In situ ellipsometry measurements of the polluted films were recorded every 20 s to assess the optical density changes at controlled humidity. ${ }^{23}$ 


\section{RESULTS AND DISCUSSION}

Structural interferential colors can be observed in the optical photograph in Figure 1(a) showing of a typical $\mathrm{TiO}_{2}$ mesoporous film applied on glass in which thickness fluctuations and defects were induced on purpose. The colors are caused by a difference in refractive index between the glass substrate and the $\mathrm{TiO}_{2}$ mesoporous coating.
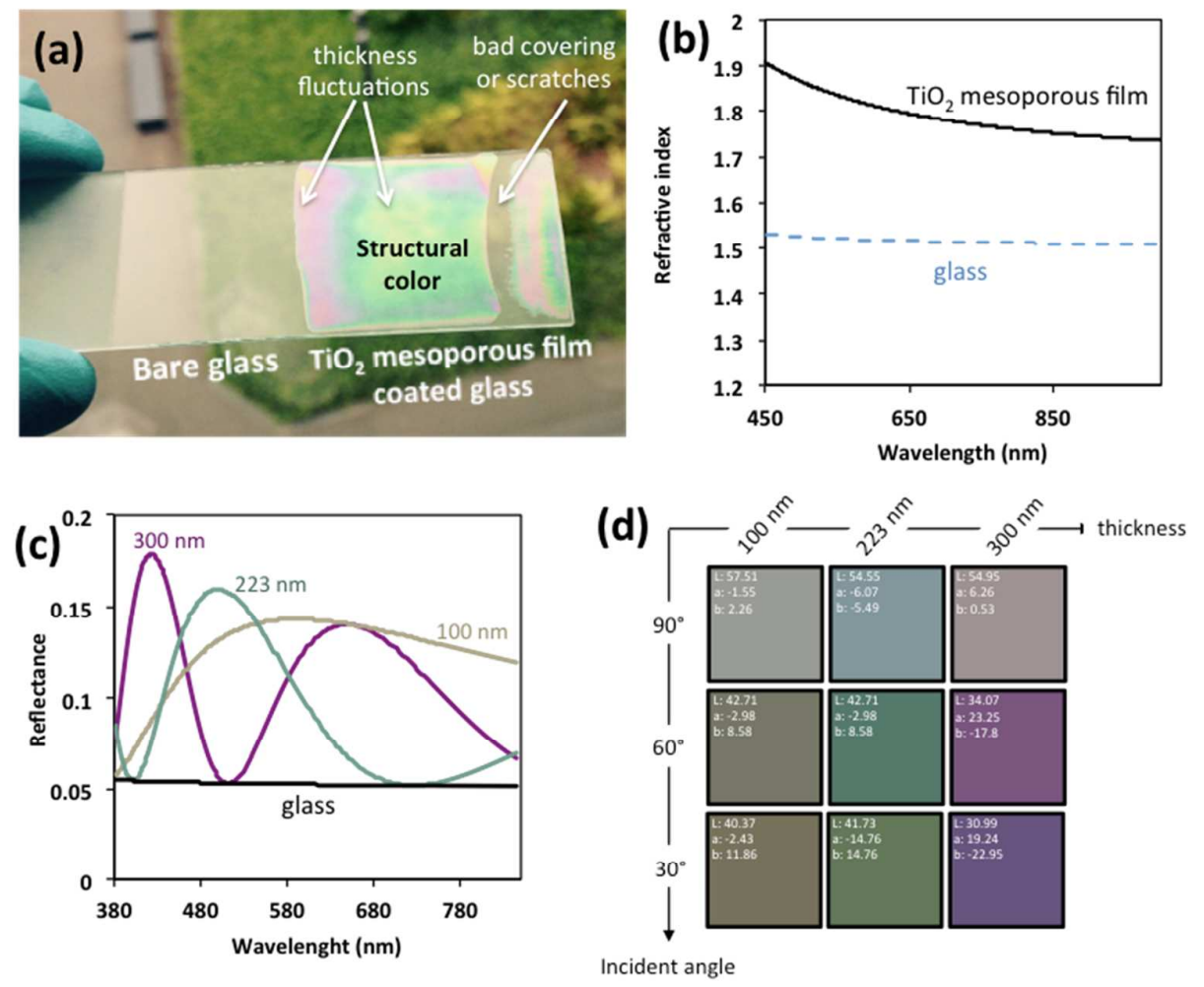

Figure 1: (a) Optical photograph of a typical $\mathrm{TiO}_{2}$ mesoporous film applied on glass exhibiting structural colors (thickness fluctuations and defects were induced on purpose); (b) Refractive index dispersion of glass substrate and $\mathrm{TiO}_{2}$ mesoporous film measured by ellipsometry; (c) Simulated reflectance spectra at $90^{\circ}$ of $\mathrm{TiO}_{2}$ mesoporous films (with variable thickness) on glass; (d) Simulated reflected colors (expressed in L*a*b coordinates) as function of thickness and incidence angle. 
This difference can be quantified by the plots of refractive index dispersions of the glass substrate and of the coating that have been obtained by ellipsometric measurements as shown in Figure 1(b). The specific shade depends on the thickness of the layer (and on the incident light angle). This effect is highlighted in Figure 1(c) and (d) in which starting from the refractive index dispersion of the substrate and of the coating, the reflectance curves and the reflected color (for different thicknesses and light incident angles) have been simulated by using the Wvase32 software.

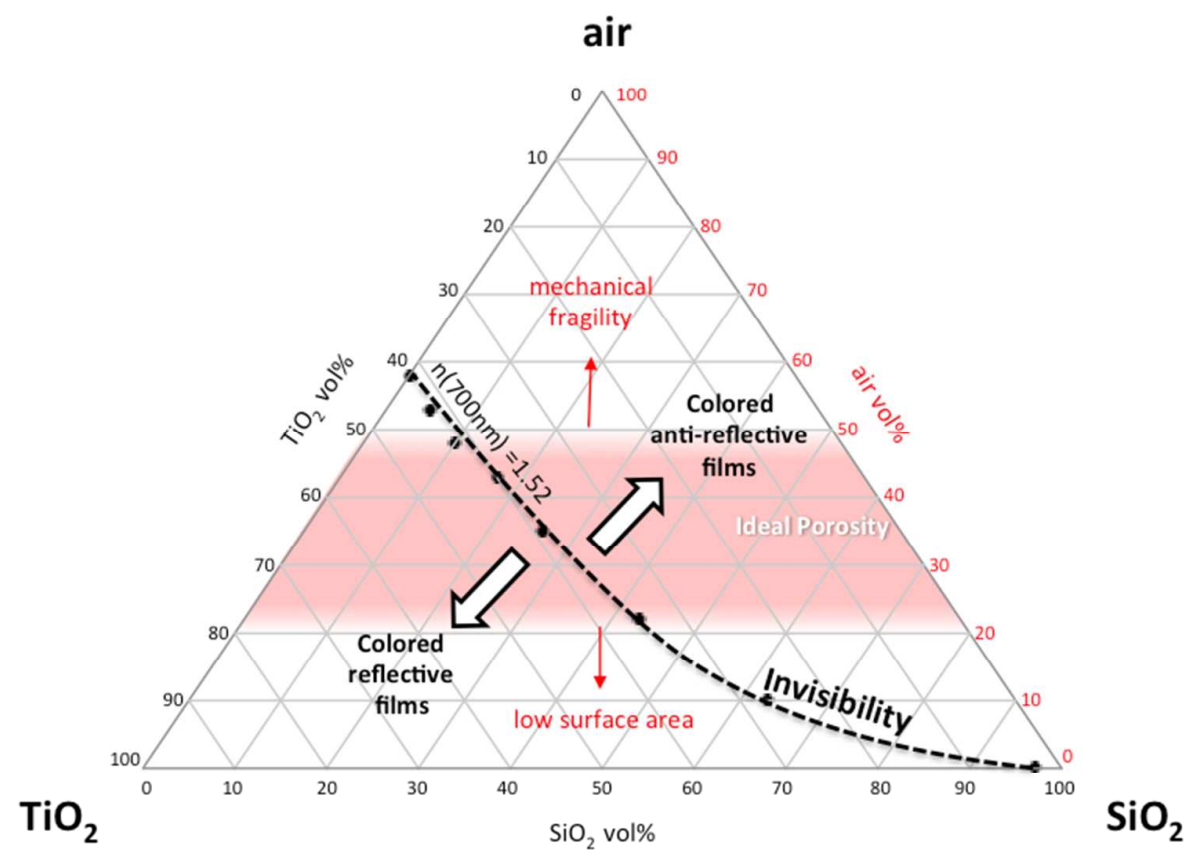

Figure 2: Simulated ternary phase diagram of $\mathrm{SiO}_{2}-\mathrm{TiO}_{2}$ mesoporous films. The dotted line indicates the "invisibility" conditions on glass calculated from experimental data of refractive index.

In order to match the refractive index of the substrate in addition to $\mathrm{TiO}_{2}$ and air, $\mathrm{SiO}_{2}$ can be added as component. For this purpose a ternary phase diagram $\mathrm{TiO}_{2} / \mathrm{SiO}_{2} /$ air was built as shown in Figure 2. The conditions for invisibility on glass, highlighted by the dotted line (at 700nm), 
were obtained by different $\mathrm{TiO}_{2} / \mathrm{SiO}_{2} /$ air mixtures and simulated by using Bruggemann effective medium approximation (BEMA) model:

$$
f_{\text {air }} \frac{\varepsilon_{\text {air }}-\varepsilon}{\varepsilon_{\text {air }}-2 \varepsilon}+f_{\text {wall }} \frac{\varepsilon_{\text {wall }}-\varepsilon}{\varepsilon_{\text {wall }}-2 \varepsilon}=0
$$

in which $\varepsilon_{\text {air }}$ and $\varepsilon_{\text {wall }}$ represent the dielectric constant of air and of the solid wall that is composed by $\mathrm{SiO}_{2}$ and $\mathrm{TiO}_{2}$. Since air, $\mathrm{SiO}_{2}$, and $\mathrm{TiO}_{2}$ do not absorb light in the considered range of wavelengths $(400-1000 \mathrm{~nm})$, the dielectric constants are taken to be the square of the refractive index values (real part of the dielectric constants). Depending on the concentration and thermal treatment the sol-gel based $\mathrm{SiO}_{2}$ and $\mathrm{TiO}_{2}$ are not necessarily phase separated but can be mixed as solid solution. For our simulation, the values of refractive index of solid wall (corresponding to the nanocomposite $\mathrm{TiO}_{2}-\mathrm{SiO}_{2}$ materials) was taken from real measurements in the case of dense films (treated at $600^{\circ} \mathrm{C}$ ). ${ }^{24}$

The targeted $\%$ vol porosity must be fixed in an "ideal" range $(20 \%-50 \%$ as highlighted in Fig.2) in order to consider two opposite technological constrains. First, films with low porous volume $\%$ are characterized by low surface area, low pore's accessibility and thus lower photocatalytic activity, a critical drawback for air-decontamination applications for instance. Second, since the mechanical stiffness (Young modulus) of a mesoporous coating is directly related to its density, ${ }^{25}$ high $\%$ porosity will result in mechanical fragile layers. For these reasons, as starting point for our study, we decided to fix the inorganic/organic molar ratio to $1 / 0.006$ in order to obtain, a priori, a porosity \%vol in the "ideal" range. Instead, in order to identify the best candidate (able to ensure invisibility, photoactivity and stiffness) we systematically varied the $\mathrm{SiO}_{2} / \mathrm{TiO}_{2}$ ratio and we investigated the role of $\mathrm{SiO}_{2}$ on the evolution of the structural, optical, mechanical and photocatalytic properties. 


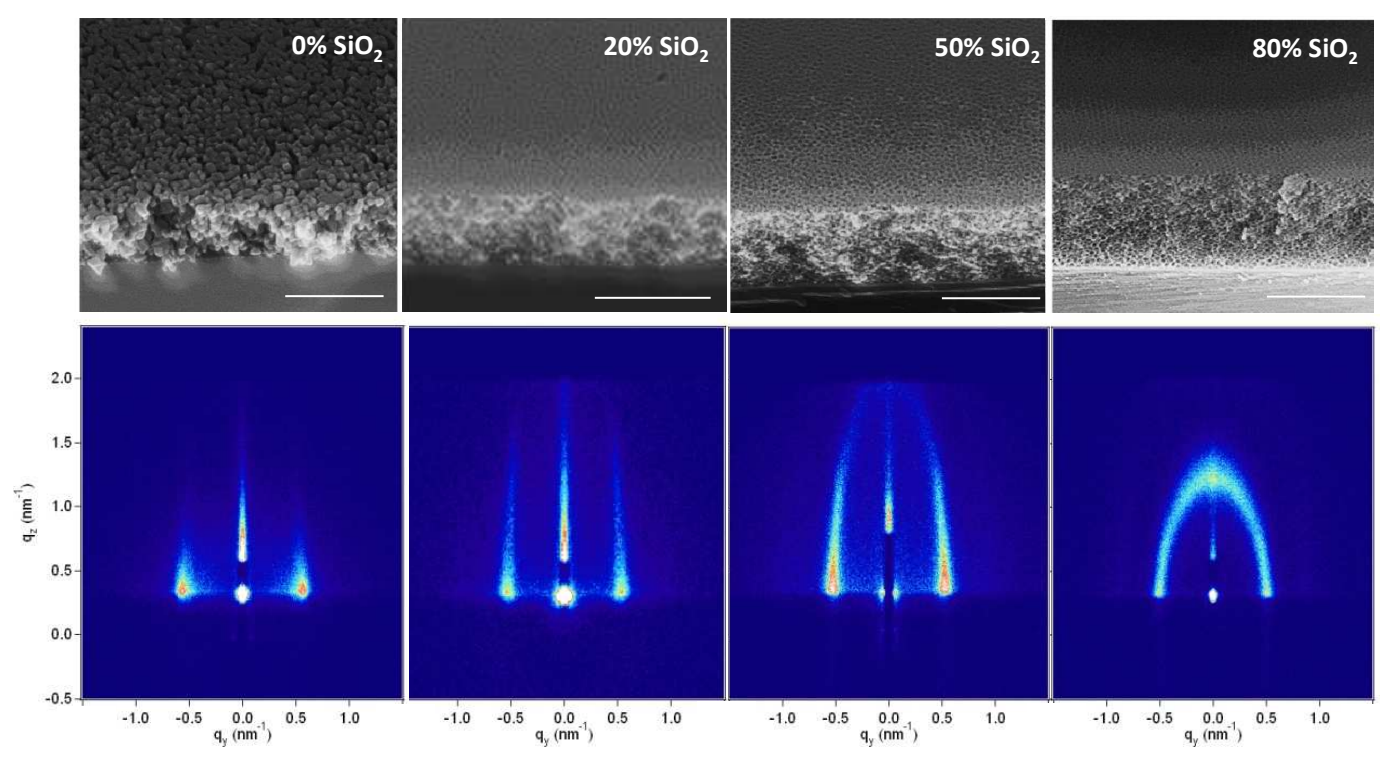

Figure 3 SEM-FEG cross section pictures and corresponding GI-SAXS patterns of selected composite $\mathrm{TiO}_{2}-\mathrm{SiO}_{2}$ mesoporous films with $\mathrm{SiO}_{2}$ content of $0 \%, 20 \%, 50 \%$, and $80 \%$. Scale bars represent $250 \mathrm{~nm}$.

\subsection{Film Structure}

Figure 3 shows the SEM images of four representative $\mathrm{TiO}_{2}-\mathrm{SiO}_{2}$ films made with $0 \%, 20 \%$, $50 \%$, and $80 \%$ of silica and their corresponding GI-SAXS patterns. Pure titania film picture exhibits the characteristic morphology of an open and highly accessible grid-like porosity, confirmed by the two parallel intense diffraction peaks of the GI-SAXS pattern at $\mathrm{q}_{\mathrm{y}}=0.052$ $\mathrm{nm}^{-1}$ coming from the domains composed of periodical planes oriented perpendicular to the substrate with a period of about $12 \mathrm{~nm}$. This $\mathrm{TiO}_{2}$ grid-like mesostructure originates from the thermally induced transformation of the amorphous titania into crystalline phase. Indeed it has already been reported that the crystallization of the initial cubic structure is accompanied by matter migration through diffusing sintering and pore merging along the [111] directions, leading to the open grid-like structure. ${ }^{26}$ 
For composite thin films, networks of well-defined elliptical pores with short-range organization are observed by SEM for $\mathrm{SiO}_{2}$ content over 20\%. Diffraction patterns obtained by GI-SAXS reveal a progressive porous structure evolution from grid-like to elliptical pores with the increase of $\mathrm{SiO}_{2}$ ratio from $2 \%$ to $100 \%$ (detailed in $\mathrm{S} 1$ ) which suggests that the previously described grid-like formation mechanism is almost not affected for low silica contents (typically below $\approx 20 \%$ ). For higher ratios, influence of silica precursors in the inorganic matrix becomes preponderant on the resulting porous structure after annealing. Indeed, increasing siliceous species during the first ageing step at $\mathrm{RH}=75 \%$ and $37^{\circ} \mathrm{C}$ induces the formation of a growing number of Ti-O-Si oxo bonds which tend to stabilize the Ti-based oligomers. Then, as already demonstrated for dense $\mathrm{TiO}_{2}-\mathrm{SiO}_{2}$ films, the short thermal treatment at $600^{\circ} \mathrm{C}$ is expected to induce the crystallization of small particles of anatase whose growth by Ostwald ripening is prevented by silica that plays the role of barrier and hinders diffusive sintering. ${ }^{24}$ Such barrierlike silica effect was observed even at $900^{\circ} \mathrm{C}$ in mesoporous powders. ${ }^{27}$ Less elongated diffraction patterns in the $\mathrm{z}$ direction of the reciprocal space are observed for the lower $\mathrm{TiO}_{2}$. This feature indicates a decrease of the anisotropy of the elliptical pores since addition of $\mathrm{SiO}_{2}$ induces a lower out-of-plain contraction of the films. The integration of the intensity profiles of GI-SAXS scattered signals recorded for $\mathrm{TiO}_{2}-\mathrm{SiO}_{2}$ porous films with $\mathrm{SiO}_{2}$ ratios from $2 \%$ to 98\% and pure silica porous films are given in Supporting Information (see S2). The position of the peak accounting for the correlation distance only slightly varies, indicating that the periodicity of the structure is globally the same regardless the $\mathrm{SiO}_{2}$ composition and the crystallinity of films (as discussed in the following parts). The corresponding structural periodicities are calculated to be in the range $11-13.5 \mathrm{~nm}$ in agreement with previous reported values (between $11 \mathrm{~nm}$ and $14 \mathrm{~nm}$ ) for F127-templated mesoporous films. ${ }^{28}$

Further investigation of the porous structures was performed by Environmental Ellipsometry Porosimetry analysis (EEP). ${ }^{29}$ Water adsorption-desorption isotherms recorded for $\mathrm{TiO}_{2}-\mathrm{SiO}_{2}$ films with $\mathrm{SiO}_{2}$ ratios varying from $0 \%$ to $100 \%$ are displayed in Figure 4(a). The shapes of 
adsorption-desorption hysteresis loops are significantly different indicating a clear evolution of the porous morphology related to the inorganic network composition. Indeed mesoporous pure titania film $\left(0 \% \mathrm{SiO}_{2}\right)$ is characterized by a narrow adsorption-desorption hysteresis suggesting that mesopores are highly interconnected through large pore windows in agreement with a gridlike mesostructure. Addition of $\mathrm{SiO}_{2}$ to the inorganic framework leads to a gradual broadening of the hysteresis loops; this is caused by a progressive decrease of the porous interconnection sizes resulting in cage-like porosity, i.e. large pores connected through smaller pore windows, which is supported by SEM images in Figure 3. In addition to the mesoporosity, the presence of micropores can be observed at low water vapor pressure $(<10 \%)$ for composites with silica content over $50 \%$. Such microporosity, typical of silica mesoporous materials templated by PEO chains, is indicative on the formation of relatively extended silica-rich nanodomains within the composite network and in contact with F127 at the surface of pores. The pore size distributions of mesoporous $\mathrm{TiO}_{2}-\mathrm{SiO}_{2}$ films were determined from adsorption and desorption curves, using the Kelvin equation:

$$
\ln \frac{P}{P_{0}}=-\frac{\gamma V_{1} \cos \theta}{r_{\mathrm{p}} R T}
$$

where $\left(P / P_{0}\right)$ is the water relative pressure and $r_{p}, \gamma, V_{l}, \Theta, R$, and $T$ are the Kelvin pore radius, the surface tension, the molar volume of liquid, the contact angle, the gas constant and the temperature, respectively. Pore sizes distributions taken from adsorption and desorption branches that are representative of the pore sizes and interconnected pore sizes (bottle-neck) respectively are plotted in S3 for silica ratios of $0 \%, 40 \%, 80 \%$, and $100 \%$. They show a relative broad distribution for pure titania films that tends to narrow when silica ratio increases. 

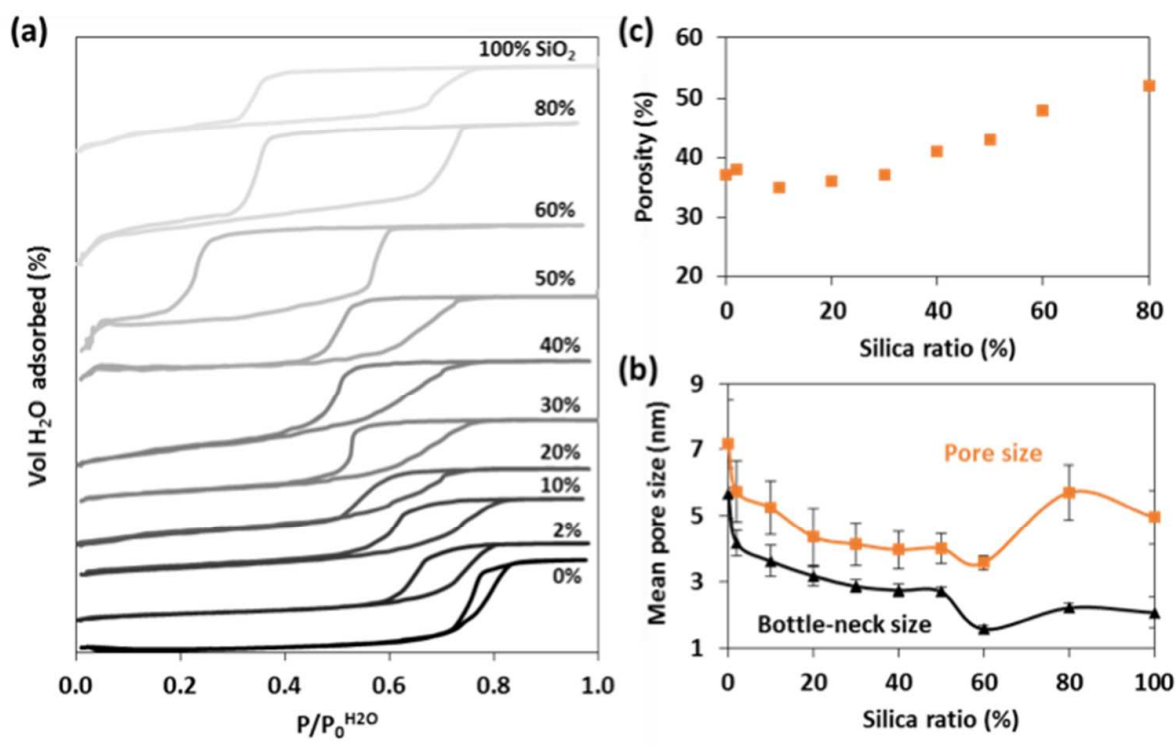

Figure 4. (a) Adsorption-desorption isotherms, (b) mean pore diameter and (c) porous volume depending on silica ratio obtained by EEP for various $\mathrm{TiO}_{2}-\mathrm{SiO}_{2}$ mesoporous films.

Evolution of average pore size and bottle-neck size as function of the silica content $\left(0 \% \leq \mathrm{SiO}_{2}\right.$ ratio $\leq 100 \%$ ), are reported in Figure $4 \mathrm{~b}$. The highest values, $7.2 \mathrm{~nm}$ and $5.7 \mathrm{~nm}$ for pore and interconnection sizes respectively, are observed for pure $\mathrm{TiO}_{2}$ film due to the pore merging caused by diffusive sintering in agreement with SEM picture (Figure 3). The progressive incorporation of silica hinders diffusive sintering and pore merging, resulting in gradual and important decrease of pore and bottle-neck sizes. The pore and bottle-neck sizes decrease down to 3.6 and $1.3 \mathrm{~nm}$ at $60 \% \mathrm{SiO}_{2}$ respectively. The same way, average pore size slowly decreases from $4.3 \mathrm{~nm}$ at $20 \% \mathrm{SiO}_{2}$ to $3.6 \mathrm{~nm}$ at $60 \% \mathrm{SiO}_{2}$. Over $60 \% \mathrm{SiO}_{2}$ content, an increase in pore size is observed, probably due to a morphological modification of the porous network (from grid-like to elliptical) in absence of crystallization (and thus in absence of migration of matter by diffusive sintering).

The film porosity $\%$ has been evaluated by using Bruggemann effective medium approximation (BEMA) model from EEP measurements ${ }^{29}$ and reported in Figure 4(c). Films show a stable 
porous volume around $35 \%$ for silica ratio inferior to $20 \%$, then it increase progressively to reach the value of $51 \%$ for silica fraction of $80 \%$. This $\% \mathrm{vol}$ porosity behavior as a function of silica confirms that: (i) the diffusive sintering, induces the partial collapse of the network, followed by densification and partial loss of the porosity during the high temperature crystallization of $\mathrm{TiO}_{2}$-rich films and (ii) amorphous silica does prevent diffusing sintering and thus avoids the collapse and large shrinkage of the porous network during thermal annealing.

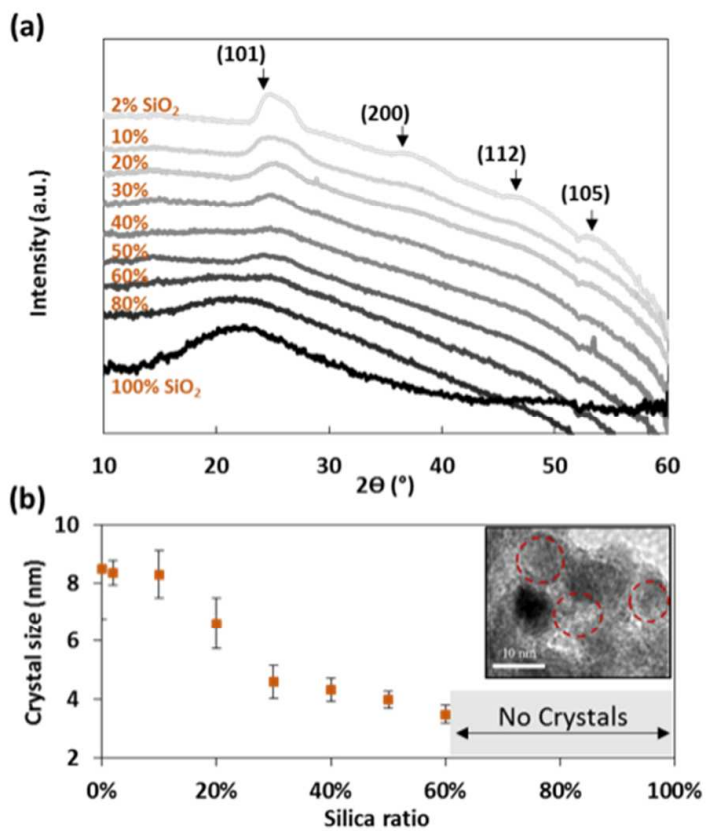

Figure 5 (a) GI-WAXS patterns of mesoporous composite $\mathrm{TiO}_{2}-\mathrm{SiO}_{2}$ films with various silica ratios in logarithm of the intensity. (b) Particle size evolution obtained by HR-TEM pictures of $\mathrm{TiO}_{2}$ anatase nanocrystals, inset the HR-TEM image of the $2 \% \mathrm{SiO}_{2}$ sample (anatase crystals are circled in red).

\subsection{Crystallinity}

Porous $\mathrm{TiO}_{2}$ layers to be photocatalytically active require the presence of anatase crystalline phase. Due to the low amount of crystalline matter and the small size of the crystallites in the films, especially for highest $\mathrm{SiO}_{2}$ loading, X-ray diffraction analysis with conventional Bragg- 
Brentano configuration does not permit to extract the diffraction signals from the background. For this reason GI-WAXS was chosen as an analytical tool for its higher sensitivity. Figure 5(a) shows the GI-WAXS plots of mesoporous composite films for various $\mathrm{SiO}_{2}$ ratios. In particular, the intensity (in logarithmic scale) is plotted as a function of $2 \Theta$. Plots exhibit four broad diffraction peaks characteristic of anatase phase evidencing the formation of $\mathrm{TiO}_{2}$ nanocrystallites. The major peak at $2 \Theta=25.4^{\circ}$ corresponds to the (101) reflection of the anatase phase, which is present in most of the mesoporous $\mathrm{TiO}_{2}-\mathrm{SiO}_{2}$ composite films except for pure $\mathrm{SiO}_{2}$ and $80 \% \mathrm{SiO}_{2}$ samples.

The other peaks in GI-WAXS patterns are respectively related to the (200), (112), and (105) planes of the anatase phase. The peaks relative intensity decreases with the increasing composition in $\mathrm{SiO}_{2}$ (from $2 \%$ to $60 \%$ ) suggesting the diminution of crystallinity in the films. This trend, observed in a previous study for dense films, ${ }^{24}$ can be attributed to a lower $\mathrm{TiO}_{2}$ content in the film but also to the fact that the crystallization temperature increases with the silica content in the $\mathrm{TiO}_{2}$ matrix due to fact that silica network, if intimately mixed with titanium oxo species, acts as a barrier to their diffusion which tends to inhibit the nucleationgrowth of $\mathrm{TiO}_{2}$ crystallites. Crystallite size evaluation by Scherrer method cannot be used with the present $\mathrm{XRD}$ diagram because the grazing incidence geometry used for the analysis induces a diffracted beam broadening that is directly dependent on the sample size. ${ }^{30}$ High-resolution transmission electron microscopy (HRTEM) images of mesoporous composite films with $\mathrm{SiO}_{2}$ ratio from $2 \%$ to $80 \%$ were recorded and are available in Supporting Information (S4). HRTEM micrographs evidence the presence of a nanoporous network, the average pore size was estimated in the range of $5 \mathrm{~nm}$ to $8 \mathrm{~nm}$ in agreement with the previous EEP characterization. Moreover nearly spherical $\mathrm{TiO}_{2}$ anatase nanocrystals can be distinguished (dark spots). For samples with the highest silica content, $\mathrm{TiO}_{2}$ crystals are embedded into $\mathrm{SiO}_{2}$ (and $\mathrm{TiO}_{2}$ ) amorphous matrix as in the case of $50 \% \mathrm{SiO}_{2}$ (see S4). The inset HR-TEM image of $2 \% \mathrm{SiO}_{2}$ sample in Fig 5 (b), single crystals (circled in red) with plane distance of $3.5 \AA$ were measured, 
which corresponds to the (101) plane of the anatase crystal in agreement with GI-WAXS results. No particles were observed for $80 \% \mathrm{SiO}_{2}$ sample which is also consistent with the GIWAXS results. The average particle size was determined by image analysis from several tens of particles from HR-TEM micrographs. The evolution of the average crystal size depending on $\mathrm{SiO}_{2}$ molar ratio is shown in Figure 5(b). It can be seen that crystal size decreases with $\mathrm{SiO}_{2}$ content from $8 \mathrm{~nm}$ to $3.5 \mathrm{~nm}$.

Based on the characterization of the crystallization and the previous structural analysis, a proposition of film formation is illustrated in Fig S5. The formation of mesostructured $\mathrm{TiO}_{2}-$ $\mathrm{SiO}_{2}$ nanocomposite films with variable Ti-Si ratio were successfully synthesized via evaporation induces self-assembly process involving amphiphilic triblock copolymer F127 together with titanate and silicate oligomers. In a large excess of $\mathrm{HCl}$, such as in our conditions due to the use of $\mathrm{TiCl}_{4}$ precursor, it has been demonstrated previously that final nanocomposites have a uniform and homogeneous framework with well dispersed silicates, in which both silicate and titanate oligomers can cross-link together, forming Ti-O-Si nanoclusters, and contributing to the mesostructured networks without phase separation. Upon deposition and self-assembly, the template $\mathrm{F} 127$ starts to decompose at $350^{\circ} \mathrm{C}$ and the mesopores are liberated. Simultaneously, the titanate species are aggregated and the homogeneous amorphous framework starts to crystallize because of the thermodynamic metastability of titania during thermal treatment. The crystallization occurs above $300^{\circ} \mathrm{C}$ depending on the composition in silica as shown by Louis et al. ${ }^{24}$ The nuclei and nanocrystals of $\mathrm{TiO}_{2}$ are formed in the pore walls. At this moment phase separation happens and anatase nanocrystals are randomly embedded in $\mathrm{SiO}_{2}$ and $\mathrm{TiO}_{2}$ amorphous matrixes. Phase separation continues to progress through $\mathrm{TiO}_{2}$ nanocrystals further growth by prolonging thermal curing time. During this stage, the silica-rich formed matrix located around the anatase crystallites further cross-links, stiffening at the same time the whole structure. Supplementary growth of $\mathrm{TiO}_{2}$ crystallites through Ostwald ripening (diffusive sintering) is then quenched by the presence of the silica 
matrix that inhibits the diffusion of titania-oxo species. The amorphous silica part of the matrix is thus responsible of nanocrystal size, the more the silica content, the smaller the size of anatase crystals, and also prevents the framework from collapsing.

\subsection{Mechanical stiffness}

The intrinsic mechanical properties of the films have been probed using EEP analysis, where the transversal deformation induced by the capillary condensation of water in the pores can be deduced from thickness evolution during water desorption. ${ }^{29}$ Figure S6 displays the superimposed plots of the variation of thickness upon water desorption for 5 representative samples at different $\% \mathrm{SiO}_{2}$. From the relative thickness curves, the transversal Young's moduli (E/GPa) were calculated using the method described in detail elsewhere. ${ }^{29}$ The calculated values of $\mathrm{E}$ as function of the $\mathrm{SiO}_{2} \%$ contents are reported in Figure 6. Pure $\mathrm{TiO}_{2}$ films, characterized by grid-like network of stacked nanocrystals, exhibits a Young modulus of $5.3 \mathrm{GPa}$, that is consistent with previous investigations. ${ }^{31}$ Addition of small amount of $\mathrm{SiO}_{2}$ in the network induces an impressive increase in stiffness with $\mathrm{E}=14.8 \mathrm{GPa}$ for the system $90 \% \mathrm{TiO}_{2}$ $10 \% \mathrm{SiO}_{2}$. As shown in the scheme in Figure, the origin of this $+160 \%$ increase in $\mathrm{E}$ can be attributed to the "brick and mortar" structure of the nanocomposite films in which $\mathrm{SiO}_{2}$ mechanically stabilizes the percolating $\mathrm{TiO}_{2}$ nanocrystals network. For $\% \mathrm{SiO} 2>10 \%$, Young moduli progressively decrease toward the E values typical of pure $\mathrm{SiO}_{2}$ mesoporous films. This progressive decrease is due to a morphological re-organization of the porous network (fromgrid-like to isolated elliptical pores) and to the fact that $\mathrm{TiO}_{2}$ nanocrystals become isolated in a pure $\mathrm{SiO}_{2}$-based amorphous matrix. 


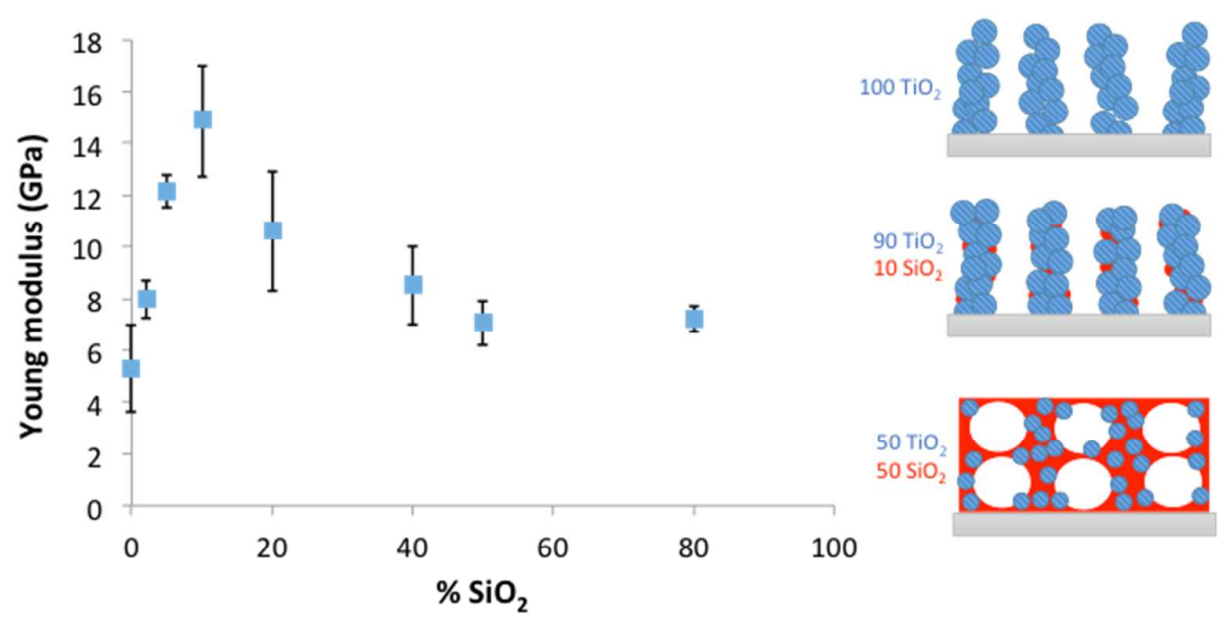

Figure 6 Evolution of the Young moduli obtained from EEP experiments as function of the $\mathrm{SiO}_{2} \%$ content; inset: schematic illustration of the expected porous structures

\subsection{Photocatalytic Activity}

The photocatalytic activity of $\mathrm{TiO}_{2}-\mathrm{SiO}_{2}$ mesoporous films in air was assessed by in situ ellipsometry. For these investigations lauric acid (LA) was used as model contaminant. LA alcoholic solution with the concentration of $0.5 \mathrm{wt} \%$ was infiltrated into the porosity by dip coating. The UV-lamp irradiation at $365 \mathrm{~nm}\left(41.1 \mathrm{~mW} . \mathrm{cm}^{-2}\right)$ was operated in a closed chamber with a controlled atmosphere maintained at constant $40 \%$ humidity and room temperature $(\mathrm{T}=$ $\left.22 \pm 2{ }^{\circ} \mathrm{C}\right)$. The humidity atmosphere was chosen at $\mathrm{RH}=40 \%$ because, as reported in our recent work, ${ }^{32}$ similar photocatalytic degradations of lauric acid were obtained for conventional encountered atmospheric humidity rates (between 20\% and 60\%). Photocatalytic activities were deduced from the variation of the film refractive index during the photo-induced decomposition of infiltrated lauric acid. Speeds of LA decomposition were compared for each $\mathrm{SiO}_{2}$ ratio, by plotting the evolution of the normalized LA/LA $\mathrm{LA}_{0}$ depending on the time of irradiation, where LA is the composition of lauric acid at the irradiation time $(\mathrm{t})$ and $\mathrm{LA}_{0}$ is the initial concentration. 
Concentrations of LA ( $\mathrm{t}$ ) were deduced from the refractive index values applying the BEMA model. $^{32}$
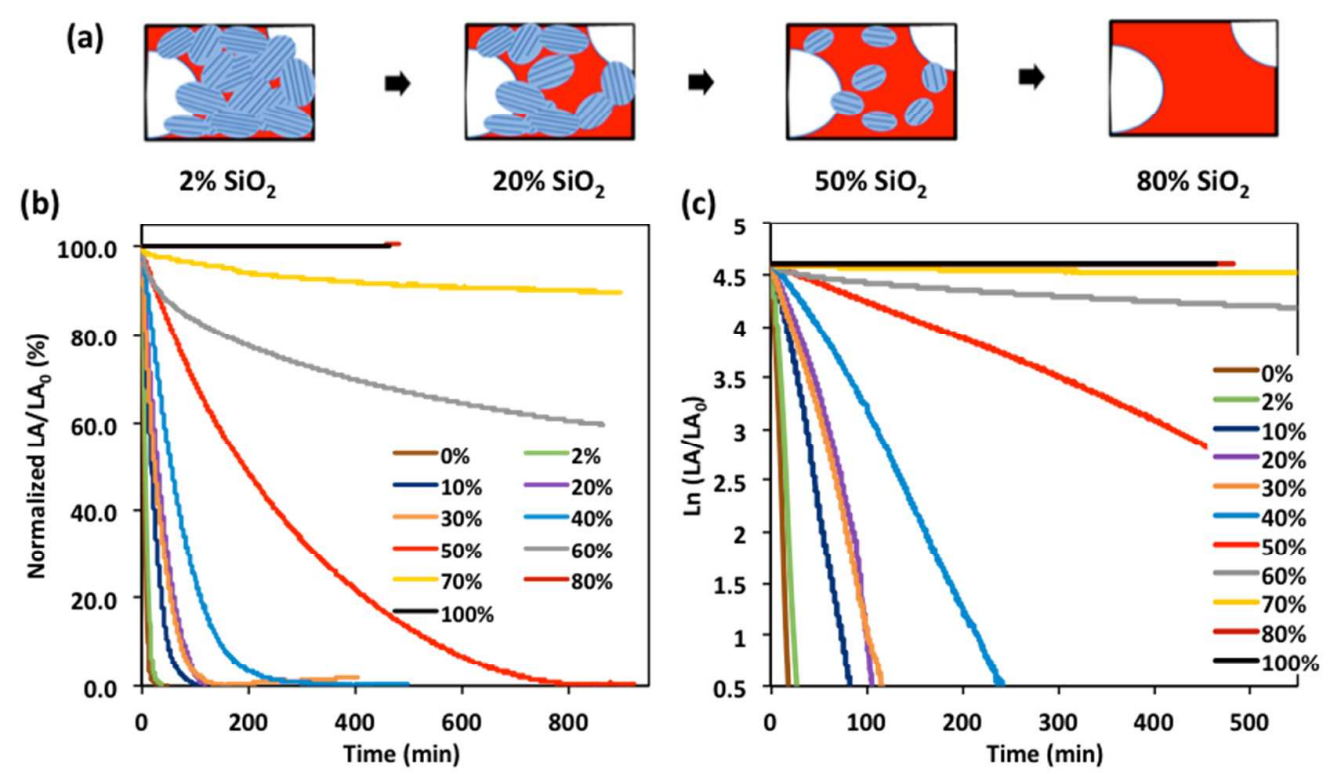

Figure 7 (a) Schematic of the $\mathrm{TiO}_{2}-\mathrm{SiO}_{2}$ nanocomposite evolution, blue particles represent $\mathrm{TiO}_{2}$ crystals and the red part is the silica (and titania) amorphous matrix. (b) Plots of normalized $\mathrm{LA} / \mathrm{LA}_{0}$ depending on the time of UV irradiation and (c) the corresponding first-order kinetic curves $\left(\mathrm{Ln}\left(\mathrm{LA} / \mathrm{LA}_{0}\right)\right.$ vs time) for mesoporous $\mathrm{TiO}_{2}-\mathrm{SiO}_{2}$ nanocomposite films with various silica ratio.

As observed in Figure 7(b), the elimination of lauric acid takes place for all samples except the ones containing $80 \%$ and $100 \%$ of $\mathrm{SiO}_{2}$ for which LA content doesn't change with time. This lack of photoactivity is consistent with the previous GI-SAXS and HR-TEM analyses, indicating the absence of anatase nanocrystals. Good photoactivity can be observed for samples containing silica up to $40 \%$ of silica; as general trend, the efficiency of the photocatalysis decreases with $\mathrm{SiO}_{2}$ content, as expected. Schematic of the structure evolution is given in Figure 
7(a), where blue particles represent titania nanocrystals and the red part is the amorphous phase of silica and titania matrix. For low $\mathrm{SiO}_{2}$ ratio, the fraction of $\mathrm{TiO}_{2}$ nanocrystals, and their accessibility, are higher leading to a higher photoactivity (higher $\mathrm{TiO}_{2}$ surface area for the radical generation and a higher surface of contact between pollutant and nanocrystals). Inversely, for higher silica content, a lower photocatalytic activity can be explained by the lower global $\mathrm{TiO}_{2}$ amount and to the fact that the nanocrystals are partially embedded in the amorphous silica network (thus less accessible to the LA molecules). Other critical factors that likely play a role on the global efficiency are: (i) the decrease of the crystal size with the increasing $\mathrm{SiO}_{2}$ content which is known to modify the photocatalytic efficiency ${ }^{33}$, (ii) the constrictions of the porosity are more pronounced in presence of $\mathrm{SiO}_{2}$ as showed in Figure 4(b), affecting probably the mobility of LA molecules, and (iii) photoactive species and products of the redox reaction (carbonated residues are known to form stable coordination bonds with $\mathrm{TiO}_{2}$ ) into the porosity.

The corresponding first-order kinetic tendencies $\left(\ln \left(\mathrm{LA} / \mathrm{LA}_{0}\right)\right.$ vs $\left.\mathrm{t}\right)$ were plot in Figure $7(\mathrm{c})$. It is observed that globally, the LA degradation evolutions follow pseudo- first-order kinetics, at least in the case of the most active samples $\left(\% \mathrm{SiO}_{2}<50 \%\right)$. However, the first order kinetic behaviors $\left(\ln \left(\mathrm{LA} / \mathrm{LA}_{0}\right)\right.$ vs $\left.\mathrm{t}\right)$ of the composite mesoporous $\mathrm{TiO}_{2} / \mathrm{SiO}_{2}$ film are not always linear suggesting that the degradation rates is not only due to the progressive consumption of LA at the pore surface but also to other factors that evolve during the experiment such as water adsorption on the pore surface. ${ }^{23}$ In order to better analyze these trends, the evolution of the kinetic constant vs time is plotted in Figure 8(a); the kinetic constant of the first order degradation reaction $(\mathrm{k})$ can be determined by using the corresponding derivatives $\mathrm{d}\left(\ln \left(\mathrm{LA} / \mathrm{LA}_{0}\right)\right) / \mathrm{dt}$ vs $\mathrm{t}$. It is clear that different $\mathrm{k}(\mathrm{t})$ absolute values and tendencies result from different film compositions. As environmental conditions $\left(\mathrm{RH}=40 \%, 20 \%\right.$ of $\mathrm{O}_{2}$, and room temperature) and concentration of impregnated LA are all controlled to be similar, discrepancies in $\mathrm{k}(\mathrm{t})$ are mainly governed by the film structure and composition. In general (and as expected) 
$\mathrm{TiO}_{2}$-rich samples provide the higher absolute values of $\mathrm{k}(\mathrm{t})$. Other considerations can be made here. First, the initial activity, $\mathrm{k}$ at $\mathrm{t}=0 \mathrm{~min}$, can be attributed to the initial presence of $\mathrm{OH}$ and $\mathrm{O}_{2}$ scavengers intrinsically adsorbed during handling and impregnation with LA.

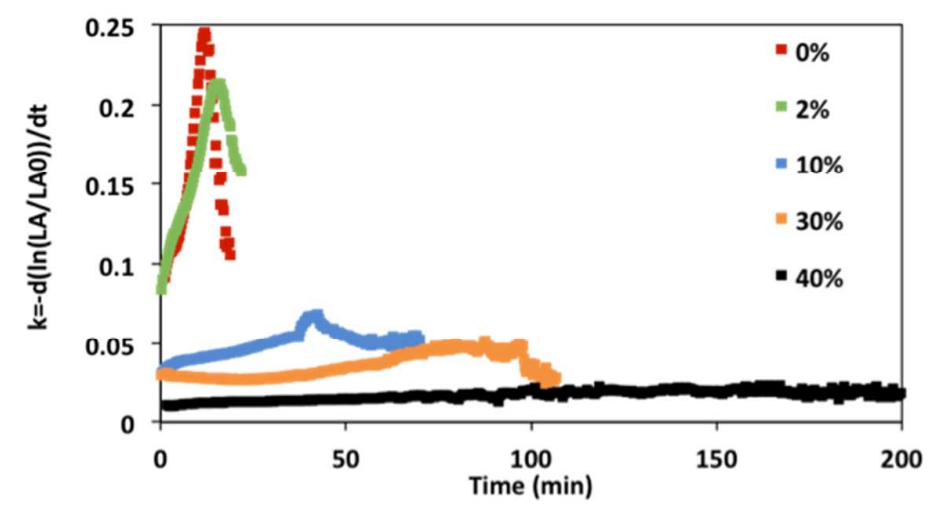

Figure 8 Curves of $-\mathrm{d}\left(\ln \left(\mathrm{LA} / \mathrm{LA}_{0}\right)\right) / \mathrm{dt}$ vs time, which represent the evolution of the kinetic constant $\mathrm{k}\left(\mathrm{min}^{-1}\right)$ all along the experiment for various ratio of silica.

Only the scavengers that are in direct contact with the active anatase surface will contribute to the initial decomposition reactions. Thus the increase of the silica content, which is logically accompanied by a decrease of the active surface into the pores, explains the lower initial $\mathrm{k}$ value at high silica content. Second, at short times the kinetic constant progressively increases since LA is decomposed at the anatase surface and liberates sites where $\mathrm{H}_{2} \mathrm{O}$ and $\mathrm{O}_{2}$ can adsorb. This induces an increase of scavenger concentration with time, causing an acceleration of the global decomposition reaction rate. After reaching a maximum, $\mathrm{k}(\mathrm{t})$ goes down progressively due to the progressive consumption of LA pollutant. Third, the $\mathrm{k}(\mathrm{t})$ maxima (which stand for the nearly end of decomposition reactions) shift to longer times with the increasing percentage of $\mathrm{SiO}_{2}$. This behavior is obviously related to the fact that less active films required more time to totally decompose LA molecules. Fourth, $\mathrm{k}(\mathrm{t})$ values are almost constant with time for $40 \% \mathrm{SiO}_{2}$ sample that is characteristic to a nearly perfect first-order kinetic. 


\subsection{Optical properties}

Optical properties of mesoporous $\mathrm{TiO}_{2}-\mathrm{SiO}_{2}$ composite layers were accessed by spectroscopic ellipsometry. Recorded data were fitted by a Cauchy model allowing the determination of the dispersion of the refractive index in the visible range (from $450 \mathrm{~nm}$ to $1000 \mathrm{~nm}$ ). Figure 9 presents the optical properties of the layers as a function of the silico-titanate composition, the dispersion curve of a bare glass substrate was added for comparison. Figure 9 (inset) summarizes the trend refractive index (at $700 \mathrm{~nm}$ ) of mesoporous $\mathrm{TiO}_{2}-\mathrm{SiO}_{2}$ nanocomposite films as function of the $\mathrm{SiO}_{2} \%$.

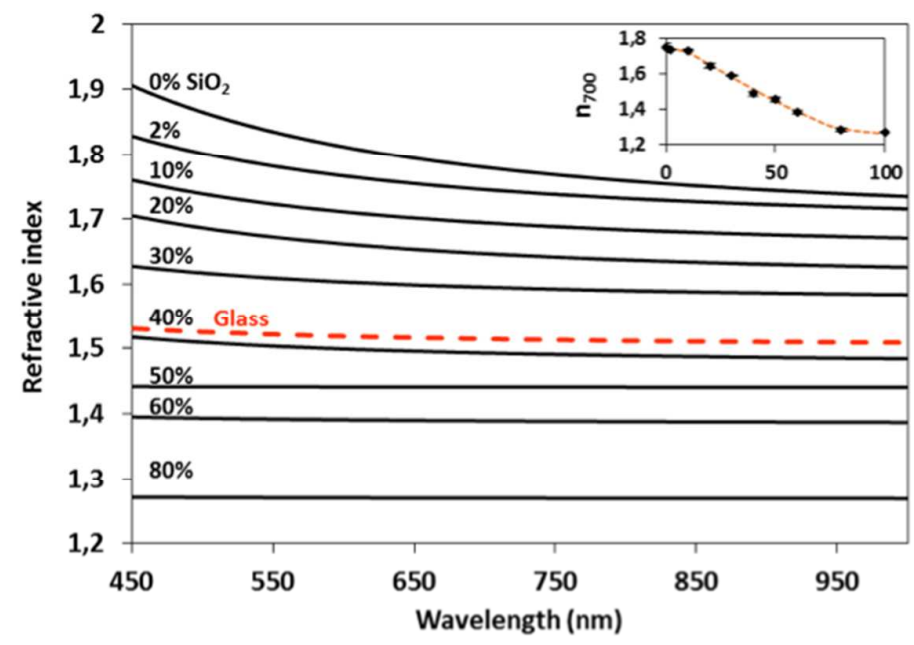

Figure 9 Evolution of the dispersion of refractive index for mesoporous $\mathrm{TiO}_{2}-\mathrm{SiO}_{2}$ composite films depending on silica content and for bare glass. (inset) Mesoporous $\mathrm{TiO}_{2}-\mathrm{SiO}_{2}$ composite films refractive index at $700 \mathrm{~nm}$ depending on silica content.

From the experimental results it is clear that the refractive index could be tuned from 1.74 to 1.27 (at $700 \mathrm{~nm}$ ) with increasing silica ratio. One notes that evolution is also partially caused by the porous volume that slightly increases as $\mathrm{SiO}_{2}$ ratio increases at constant porogen agent molar ratio due to the thermal-induced framework restructuration as discussed previously.

From these results, we can evaluate the optical behavior of the composite layers if applied on glass substrate. Samples having dispersion of refractive index higher than bare glass will behave 
as reflective coatings, typically for layers with $\mathrm{SiO}_{2}$ ratio superior to $40 \%$. At the opposite, layers with lower refractive index $\left(\mathrm{SiO}_{2}<40 \%\right)$ will behave as (poor) antireflective coatings. In both cases, a structural color, resulting from destructive and constructive reflections, always appears. Interestingly, the $40 \% \mathrm{SiO}_{2}$ coating exhibits a very similar refractive index dispersion as respect to the bare glass substrate. In this case, the coating will likely behave as an optically "invisible" layer on glass.

\subsection{Invisible, photocatalytic films on glass}

To validate the concept of "invisible" photocatalytic layer, glass substrates were coated with the $60 \% \mathrm{TiO}_{2}-40 \% \mathrm{SiO}_{2}$ layers, the most promising candidate for "invisibility" according with the optical analyses. The same experiments were conducted with the pure mesoporous titania films as reference. In order to better evaluate the appearance/suppression of the structural colors, in both cases, three different thicknesses were obtained by tuning the withdrawal speed during dip-coating $\left(3,5\right.$ and $\left.15 \mathrm{mms}^{-1}\right)$. The corresponding transmittance spectra of both types of stacks and of a bare glass substrate are plotted in Figure 10(a) for wavelength comprised between $400 \mathrm{~nm}$ and $800 \mathrm{~nm}$ and different thickness of coatings. Pure titania mesoporous layers exhibit the typical behavior of reflective coatings with decrease of transmittance values up to more than $20 \%$ and fluctuations that depend on the layers thickness. Starting from the experimental transmission curves, the simulated reflected colors of pure mesoporous $\mathrm{TiO}_{2}$ films are shown in Figure 10 (b). As expected, a structural color appears and its shade depends significantly on the thickness and the incident angle. Oppositely, the transmittance curves of the mesoporous $60 \% \mathrm{TiO}_{2}-40 \% \mathrm{SiO}_{2}$ layers are nearly identical to the one of the bare substrate. The efficiency in suppression of the structural colors can be visually observed in Figure 10 (b) in which no shade is present, with a low dependency towards coating thickness and incidence angle. 

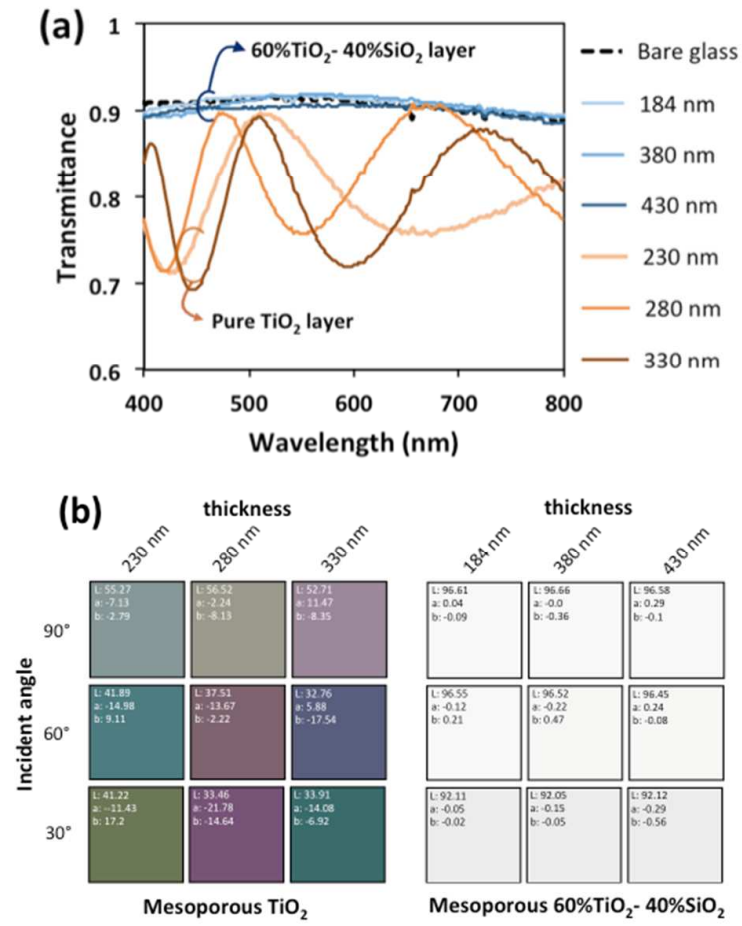

Figure 10 (a) Transmittance of mesoporous pure $\mathrm{TiO}_{2}$ and $60 \% \mathrm{TiO}_{2}-40 \% \mathrm{SiO}_{2}$ one side coated glass substrates with various thickness recorded in visible spectrum. (b) Simulated reflected colors (expressed in $\mathrm{L}^{*} \mathrm{a} * \mathrm{~b}$ coordinates) as function of thickness and incidence angle.

The photocatalytic activity of the $60 \% \mathrm{TiO}_{2}-40 \% \mathrm{SiO}_{2}$ "invisible" film on glass was confirmed by monitoring its transmittance spectra along a pollution/depollution cycle. The film was first artificially polluted with lauric acid, following the same procedure of the ellipsometric analysis. As shown in Figure 11 after infiltration by lauric acid, the increase in refractive index of the coating results in a decrease in transmittance. The sample was then exposed to UV light $(365 \mathrm{~nm})$ for 3 hours; after UV irradiation, the sample re-gains its initial transmission performances indicating that the pollutant was efficiently decomposed. 


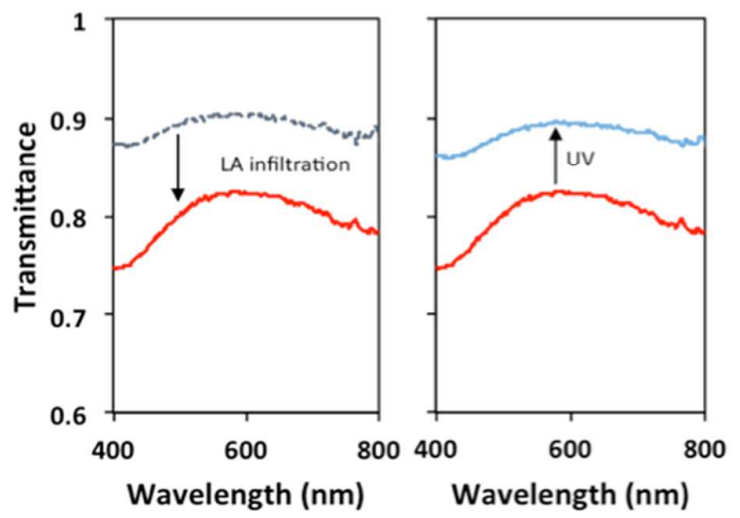

Figure 11 Transmittance curves of mesoporous $60 \% \mathrm{TiO}_{2}-40 \% \mathrm{SiO}_{2}$ film infiltrated by Lauric Acid (red curve) and after UV irradiation

\section{CONCLUSIONS}

Summarizing, in this work we investigated the role of $\mathrm{SiO}_{2}$ to suppress the structural color of mesoporous $\mathrm{TiO}_{2}$-based coatings on glass. Nanocomposite $\mathrm{SiO}_{2}-\mathrm{TiO}_{2}$ mesoporous films were fabricated by liquid deposition route and systematically characterized. We highlight that addition of $\mathrm{SiO}_{2}$ on $\mathrm{TiO}_{2}$-based coatings resulted in a progressive porous network reconfiguration from "open" grid-like structure to more "isolated" elliptical pores. We also revealed that $10 \%$ of $\mathrm{SiO}_{2}$ leads to an impressive improvement $(+160 \%)$ in stiffness as respect to pure $\mathrm{TiO}_{2}$ mesoporous layers. Supported by optical simulation, it is shown that depending on the composition, such mesoporous coatings normally behaved as colored antireflective and reflective coatings. Importantly, we demonstrated coatings characterized by a precise composition $\left(60 \% \mathrm{TiO}_{2}-40 \% \mathrm{SiO}_{2}\right)$ and porosity volume $(40 \% \mathrm{vol})$ performed as invisible layers with improved mechanical stiffness and still high photocatalytic activity. 


\begin{abstract}
ASSOCIATED CONTENT
Supporting Information.

GI-SAXS and pore size distribution data as well as HR-TEM pictures of $\mathrm{TiO}_{2}$ nanocrystals and optical simulations of mesoporous $\mathrm{TiO}_{2}-\mathrm{SiO}_{2}$ composite thin films. These materials are available free of charge via the internet at http://pubs.acs.org.
\end{abstract}

\title{
AUTHOR INFORMATION \\ Corresponding Author \\ *E-mail: marco.faustini@upmc.fr
}

\section{ACKNOWLEDGMENT}

We thank D. Montero for SEM-FEG microscopy conducted on a Hitachi Su-70 + Oxford XMax facilited by the IMPC (FR2482) financially supported by the C'Nano projects of the Region Ilede-France, and P. Legriel and M. Selmane for HR-TEM and GI-SAXS experiments. Boudot M. is an International Research Fellow of the Japan Society for the Promotion of Science.

\section{REFERENCES}

1. Rasmussen, S. C., Applications to Chemical Apparatus. In How Glass Changed the World: The History and Chemistry of Glass from Antiquity to the 13th Century, Rasmussen, S. C., Ed. Springer Berlin Heidelberg: Berlin, Heidelberg, 2012, pp 51-67.

2. Banerjee, S.; Dionysiou, D. D.; Pillai, S. C., Self-Cleaning Applications of TiO2 by Photo-induced Hydrophilicity and Photocatalysis. Appl. Catal., B 2015, 176-177, 396-428. 
3. Paz, Y.; Luo, Z.; Rabenberg, L.; Heller, A., Photooxidative Self-cleaning Transparent Titanium-dioxide Films on Glass. J. Mater. Res. 1995, 10 (11), 2842-2848.

4. Maggos, T.; Bartzis, J. G.; Liakou, M.; Gobin, C., Photocatalytic Degradation of NOx Gases using TiO2-containing Paint: A Real Scale Study. J. Hazard. Mater. 2007, 146 (3), 668673.

5. Ao, C. H.; Lee, S. C.; Yu, J. Z.; Xu, J. H., Photodegradation of Formaldehyde by Photocatalyst TiO2: Effects on the Presences of NO, SO2 and VOCs. Appl. Catal., B 2004, 54 (1), 41-50.

6. Ao, C. H.; Lee, S. C.; Mak, C. L.; Chan, L. Y., Photodegradation of Volatile Organic Compounds (VOCs) and NO for Indoor Air Purification using TiO2: Promotion Versus Inhibition Effect of NO. Appl. Catal., B 2003, 42 (2), 119-129.

7. Li, W.; Wu, Z.; Wang, J.; Elzatahry, A. A.; Zhao, D., A Perspective on Mesoporous TiO2 Materials. Chem. Mater. 2014, 26 (1), 287-298.

8. Yang, P. D.; Zhao, D. Y.; Margolese, D. I.; Chmelka, B. F.; Stucky, G. D., Block Copolymer Templating Syntheses of Mesoporous Metal Oxides with Large Ordering Lengths and Semicrystalline Framework. Chem. Mater. 1999, 11 (10), 2813-2826.

9. Soler-Illia, G. J. A. A.; Angelome, P. C.; Fuertes, M. C.; Grosso, D.; Boissiere, C., Critical Aspects in the Production of Periodically Ordered Mesoporous Titania Thin Films. Nanoscale 2012, 4 (8), 2549-2566.

10. Du, J.; Lai, X. Y.; Yang, N. L.; Zhai, J.; Kisailus, D.; Su, F. B.; Wang, D.; Jiang, L., Hierarchically Ordered Macro-Mesoporous TiO2-Graphene Composite Films: Improved Mass Transfer, Reduced Charge Recombination, and Their Enhanced Photocatalytic Activities. $A C S$ Nano 2011, 5 (1), 590-596.

11. Ceratti, D. R.; Louis, B.; Paquez, X.; Faustini, M.; Grosso, D., A New Dip Coating Method to Obtain Large-Surface Coatings with a Minimum of Solution. Adv. Mater. 2015, 27 (34), 4958-4962. 
12. Fattakhova-Rohlfing, D.; Zaleska, A.; Bein, T., Three-Dimensional Titanium Dioxide Nanomaterials. Chem. Rev. 2014, 114 (19), 9487-9558.

13. Stathatos, E.; Lianos, P.; Falaras, P.; Siokou, A., Photocatalytically Deposited Silver Nanoparticles on Mesoporous TiO2 Films. Langmuir 2000, 16 (5), 2398-2400.

14. Young, T., The Bakerian Lecture: On the Theory of Light and Colours. Philos. Trans. R. Soc. London 1802, 92, 12-48.

15. Kubota, H., On the Interference Color of Thin Layers on Glass Surface. J. Phys. Soc. Jpn. 1950, 5 (1), 10-14.

16. Faustini, M.; Ceratti, D. R.; Louis, B.; Boudot, M.; Albouy, P.-A.; Boissiere, C.; Grosso, D., Engineering Functionality Gradients by Dip Coating Process in Acceleration Mode. ACS Appl. Mater. Interfaces 2014, 6 (19), 17102-17110.

17. Scriven, L. E. In Physics and Applications of Dip Coating and Spin Coating, MRS proceedings, Cambridge Univ Press, 1988; 717.

18. Allain, E.; Besson, S.; Durand, C.; Moreau, M.; Gacoin, T.; Boilot, J. P., Transparent Mesoporous Nanocomposite Films for Self-Cleaning Applications. Adv. Funct. Mater. 2007, 17 (4), 549-554.

19. Guldin, S.; Kohn, P.; Stefik, M.; Song, J.; Divitini, G.; Ecarla, F.; Ducati, C.; Wiesner, U.; Steiner, U., Self-Cleaning Antireflective Optical Coatings. Nano Letters 2013, 13 (11), 5329-5335.

20. Innocenzi, P.; Malfatti, L.; Kidchob, T.; Falcaro, P., Order- Disorder in Self-Assembled Mesostructured Silica Films: A Concepts Review. Chem. Mater. 2009, 21 (13), 2555-2564.

21. Lu, Y.; Ganguli, R.; Drewien, C. A.; Anderson, M. T.; Brinker, C. J.; Gong, W.; Guo, Y.; Soyez, H.; Dunn, B.; Huang, M. H.; Zink, J. I., Continuous Formation of Supported Cubic and Hexagonal Mesoporous Films by Sol-gel Dip-coating. Nature 1997, 389 (6649), 364-368. 
22. Faustini, M.; Louis, B.; Albouy, P. A.; Kuemmel, M.; Grosso, D., Preparation of Solgel Films by Dip-coating in Extreme Conditions. J. Phys. Chem. C 2010, 114 (17), 7637-7645. 23. Li, R.; Faustini, M.; Boissière, C. d.; Grosso, D., Water Capillary Condensation Effect on the Photocatalytic Activity of Porous TiO2 in Air. J. Phys. Chem. C 2014, 118 (31), 1771017716.

24. Louis, B.; Krins, N.; Faustini, M.; Grosso, D., Understanding Crystallization of Anatase into Binary SiO2/TiO2 Sol- Gel Optical Thin Films: An in Situ Thermal Ellipsometry Analysis. J. Phys. Chem. C 2011, 115 (7), 3115-3122.

25. Fan, H.; Hartshorn, C.; Buchheit, T.; Tallant, D.; Assink, R.; Simpson, R.; Kissel, D. J.; Lacks, D. J.; Torquato, S.; Brinker, C. J., Modulus-density Scaling Behaviour and Framework Architecture of Nanoporous Self-assembled Silicas. Nat. Mater. 2007, 6 (6), 418-423.

26. Grosso, D.; Soler-Illia, G. J. d. A. A.; Crepaldi, E. L.; Cagnol, F.; Sinturel, C.; Bourgeois, A.; Brunet-Bruneau, A.; Amenitsch, H.; Albouy, P. A.; Sanchez, C., Highly Porous TiO2 Anatase Optical Thin Films with Cubic Mesostructure Stabilized at $700{ }^{\circ} \mathrm{C}$. Chem. Mater. 2003, 15 (24), 4562-4570.

27. Dong, W.; Sun, Y.; Lee, C. W.; Hua, W.; Lu, X.; Shi, Y.; Zhang, S.; Chen, J.; Zhao, D., Controllable and Repeatable Synthesis of Thermally Stable Anatase Nanocrystal-Silica Composites with Highly Ordered Hexagonal Mesostructures. J. Am. Chem. Soc. 2007, 129 (45), 13894-13904.

28. Innocenzi, P.; Malfatti, L.; Soler-Illia, G. J. A. A., Hierarchical Mesoporous Films: From Self-Assembly to Porosity with Different Length Scales. Chem. Mater. 2011, 23 (10), 2501-2509.

29. Boissiere, C.; Grosso, D.; Lepoutre, S.; Nicole, L.; Bruneau, A. B.; Sanchez, C., Porosity and Mechanical Properties of Mesoporous Thin Films Assessed by Environmental Ellipsometric Porosimetry. Langmuir 2005, 21 (26), 12362-12371. 
30. Faustini, M.; Nicole, L.; Boissiere, C.; Innocenzi, P.; Sanchez, C.; Grosso, D., Hydrophobic, Antireflective, Self-Cleaning, and Antifogging Sol-Gel Coatings: An Example of Multifunctional Nanostructured Materials for Photovoltaic Cells. Chem. Mater. 2010, 22 (15), 4406-4413.

31. Tetelin, A.; Blanc, L.; Tortissier, G.; Dejous, C.; Rebière, D.; Boissière, C. Guided SHSAW Characterization of Elasticity Variations of Mesoporous TiO2 Sensitive Films during Humidity Sorption, Sensors 2010 IEEE, 2010, 2136-2140.

32. Li, R.; Faustini, M.; Boissiere, C.; Grosso, D., Water Capillary Condensation Effect on the Photocatalytic Activity of Porous TiO2 in Air. J. Phys. Chem. C 2014, 118 (31), 1771017716.

33. Chae, S. Y.; Park, M. K.; Lee, S. K.; Kim, T. Y.; Kim, S. K.; Lee, W. I., Preparation of Size-Controlled TiO2 Nanoparticles and Derivation of Optically Transparent Photocatalytic Films. Chem. Mater. 2003, 15 (17), 3326-3331. 


\section{Table of Contents}

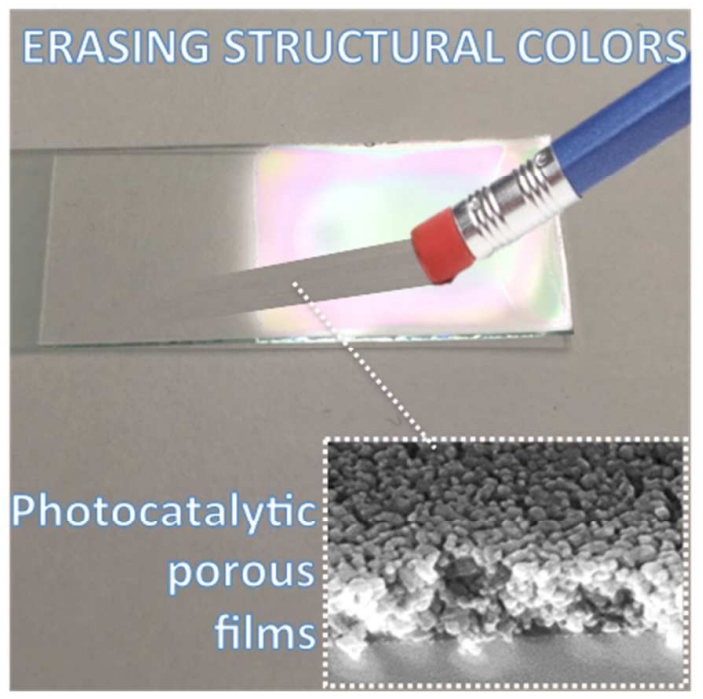

